\title{
ON FRACTIONAL MEAN VALUE THEOREMS ASSOCIATED WITH HADAMARD FRACTIONAL CALCULUS AND APPLICATION
}

\author{
Li Ma, Chengcheng LiU, Ruilin LiU, Bo Wang And YiXuAn Zhu
}

\begin{abstract}
This paper is mainly to establish generalized mean value theorems involved with left and right Hadamard fractional calculus. In light of suitable absolutely continuous spaces and auxiliary scaling function, the novel Taylor type mean value theorem and Cauchy type mean value theorem are demonstrated in the functional space generated by logarithmic basis, respectively. Additionally, several indispensable examples are given to verify the effectiveness of our theoretical results.
\end{abstract}

Mathematics subject classification (2010): 26A03, 26A24, 41A58.

Keywords and phrases: Hadamard fractional calculus, mean value theorems, logarithmic series expansions.

\section{REFERENCES}

[1] R. MetZler, J. KLAFTER, The restaurant at the end of the random walk: recent developments in the description of anomalous transport by fractional dynamics, Journal of Physics A-Mathematical and General, 2004, 37 (31): R161-R208.

[2] R. SAKThivel, N. I. MAhmudov, J. J. Nieto, Controllability for a class of fractional-order neutral evolution control systems, Applied Mathematics and Computation, 2012, 218 (20): 10334-10340.

[3] E. KASLIK, S. SivASUNDARAM, Nonlinear dynamics and chaos in fractional-order neural networks, Neural Networks, 2012, 32: 245-256.

[4] S. Mondal, N. BAiragi, G. M. N'Guerekata, Global stability of a Leslie-Gower-type fractional order tritrophic food chain model, Fractional Differential Calculus, 2019, 9 (1): 149-161.

[5] M. Magdziarz, A. Weron, K. Burnecki, J. Klafter, Fractional brownian motion versus the continuous-time random walk: A simple test for subdiffusive dynamics, Physical Review Letters, 2009, 103 (18): 180602.

[6] A. Coronel-Escamilla, J. F. Gomez-Aguilar, L. Torres, R. F. Escobar-Jimenez, a numerical solution for a variable-order reaction-diffusion model by using fractional derivatives with non-local and non-singular kernel, Physica A-Statistical Mechanics and its Applications, 2018, 491: 406-424.

[7] Q. YANG, F. W. LIU, I. TURNER, Numerical methods for fractional partial differential equations with Riesz space fractional derivatives, Applied Mathematical Modelling, 2010, 34 (1): 200-218.

[8] I. Podlubny, Fractional Differential Equations, San Diego, Academic Press, 1999.

[9] A. A. Kilbas, H. M. SRivastava, J. J. Trujillo, Theory and Applications of Fractional Differential Equations, Amsterdam, Elsevier, 2006.

[10] B. Toni, K. Williamson, N. Ghariban, D. Haile, Z. F. Xie, Bridging Mathematics, Statistics, Engineering and Technology, New York, Springer, 2012.

[11] S. Blaszczyk, R. Jachowicz, P. Duch, M. Laski, A. Wulkiewicz, P. Ostalczyk, D. SANKOWSKI, Application of fractional-order derivative for edge detection in mobile robot system, Singapore, World Scientific Publishing Company, 2014.

[12] J. E. PeČarić, I. Perić, H. M. SRivastava, A family of the Cauchy type mean-value theorems, Journal of Mathematcal Analysis and Applications, 2005, 306 (2): 730-739.

[13] K. Diethelm, The mean value theorems and a Nagumo-type uniqueness theorem for Caputo's fractional calculus, Fractional Calculus and Applied Analysis, 2012, 15 (2): 304-313. 
[14] P. Guo, C. P. LI, G. R. Chen, On the fractional mean-value theorem, International Journal of Bifurcation and Chaos, 2012, 22 (5): 1250104.

[15] A. FernANDEZ, D. BALEANU, The mean value theorem and Taylor's theorem for fractional derivatives with Mittag-Leffler kernel, Advances in Difference Equations, 2018, 2018: 86.

[16] E. R. NWAEZE, A mean value theorem for the conformable fractional calculus on arbitrary time scales, Progress in Fractional Differentiation and Applications, 2016, 2 (4): 287-291.

[17] A. A. Kilbas, Hadamard-type fractional calculus, Journal of the Korean Mathematical Society, 2001, 38 (6): 1191-1204.

[18] P. L. Butzer, A. A. Kilbas, J. J. Trujillo, Fractional calculus in the Mellin setting and Hadamard-type fractional integrals, Journal of Mathematical Analysis and Applications, 2002, 269 (1): $1-27$.

[19] L. MA, C. P. LI, On Hadamard fractional calculus, Fractals, 2017, 25 (3): 1750033.

[20] L. MA, C. P. LI On finite part integrals and Hadamard-type fractional derivatives, Journal of Computational and Nonlinear Dynamics, 2018, 13 (9): 090905.

[21] L. MA, Comparison theorems for Caputo-Hadamard fractional differential equations, Fractals, 2019, 27 (3): 1950036.

[22] L. MA, Blow-up phenomena profile for Hadamard fractional differential systems in finite time, Fractals, 2019, 27 (6): 1950093.

[23] L. MA, On the kinetics of Hadamard-type fractional differential systems, Fractional Calculus and Applied Analysis, 2020, 23 (2): 553-570.

[24] B. Ahmad, A. Alsaedi, S. K. Ntouyas, J. TARiboon, Hadamard-Type Fractional Differential Equations, Inclusions and Inequalities, Switzerland, Springer International Publishing, 2017.

[25] R. Garra, F. Mainardi, G. SPADA, A generalization of the Lomnitz logarithmic creep law via Hadamard fractional calculus, Chaos, Solitons and Fractals, 2017, 102: 333-338. 